that recommended by the Commission. I should like, however, to receive an expression of opinion that notwithstanding the progress made towards unanimity in this matter, the course recommended by the Commission-the appointment of a statutory commission to frame the future statutes and to reconstitute the University - is the only one to insure the scheme from further delay and perhaps ultimate failure.

Sir H. Roscoe said that the matter had not been formally brought before the Senate, but he should be expressing the view of his colleagues if he said that the question whether this reorganisation was to take place by charter, or, under the recommendation of the Cowper Commission, by a statutory commission had engaged their attention for many years, and that they had come to the conclusion that in consequence of the complexity of the question the difficulty of drawing up in black and white any statement in the form of a charter would be extremely great. The suggestion that the Senate might act under powers as a statutory commission had not been brought before them, and he could say nothing about it. But as between a new charter and a statutory commission the consensus of opinion was in favour of the commission rather than the charter.

Mr. Anstey, as a long-standing member of the Senate and a member of the Cowper Commission, thought that a statutory commission was absolutely essential. The matter had never been presented to the Senate, but the difficulties were insuperable in dealing with the details.

The Duke of Devonshire: The suggestion which may still probably be made is that legislation has become unnecesary when the approach to unanimity is so nearly complete that everything which is required might be done by charter on the motion of the Senate and not under statutory powers. London University under its existing charter possesses powers to alter its statutes and regulations subject to the approval of Convocation, and the suggestion which I understand might be made was that that course might be adopted with a reasonable prospect of success. I understand, however, that Mr. Anstey has expressed the unanimous, or almost unanimous, opinion of those present that that is not the case, and that nothing short of a body armed with statutory powers, such as the proposed commission, would be sufficient.

Sir Joshua Fitch said the question had been amply discussed by the Royal Commission, and their deliverances were unanimous and unanswerable. The difficulty of submitting such a charter to a scattered body like Convocation was too serious for the attempt to be practicable.

Mr. Anstey explained that the unanimity was only on the point that there should be a statutory commission.

After thanking the Duke of Devonshire for his reception of the deputation, the members of it withdrew.

\section{THE FORTHCOMING INTERNATIONAL CONGRESS OF ZOOLOGY.}

F NGLISH zoologists ought to learn with satisfaction E that the International Congress, which has already met in France, Russia, and Holland, will meet in this country next August. The first Congress took place in Paris at the time of the International Exhibition in 1889 . For some reason-perhaps the cholera-the second meeting, held in Moscow in 1892 , was not largely attended. The third meeting at Leyden, in 1895 , was attended by 173 zoologists with their wives and other members of their families.

It is to be hoped and expected that the meeting at Cambridge will be still more largely attended, and there is every reason to hope that the German element, which has not been conspicuous at previous meetings, will be better represented in this country.

We have already stated that, unfortunately, owing to the condition of his health and his numerous and arduous official duties, Sir William Flower, K.C.B., F.R.S., who was naturally elected President for the fourth Congress at the meeting in Leyden, has felt constrained to resign his post. To the general satisfaction of zoologists the Right Hon. Sir John Lubbock, Bart., F.R.S., was appointed in his place. At Cambridge a strong Committee has been formed, which is now actively engaged making the NO. I 474 , VOL. 57$]$ necessary preparations for the coming together of zoologists, and for their suitable reception and entertainment.

It may be mentioned by the way that August 23 and the town of Cambridge are the date and place of meeting, not only of zoologists, but also of physiologists, who intend to hold a Congress in the same week.

The Executive Committee of the Congress, selected from the General Committee, has somewhat varied the mode of invitation which obtained at previous Congresses. The invitation to the Congress is signed solely by English zoologists, and, on the whole, the list may be said to be a representative one, although it is to be regretted that Mr. A. K. Wallace and Prof. Allman have felt the weight of years too heavy to justify them in taking any part in this Congress. Our fellow zoologists in the Colonies and India have been invited to join the General Committee, and steps are being taken to invite the Indian and Colonial Governments to send delegates to the Congress. The more eminent foreign zoologists have been invited to form the Committee of Patronage which is always established at these Congresses, and we are glad to hear that already more than sixty have agreed to become members of this Committee, and a number have declared their intention of being present at the meeting if they possibly can. Among these may be mentioned Prof.-Milne-Edwards (of Paris), Prof. Hubrecht (of Utrecht), and Prof. Kowalevsky (of St. Petersburg).

Visitors to earlier Congresses always brought away an account of generous hospitality, and there can be no doubt that our foreign friends will be charmed at meeting in a place so strange and interesting to them as an English University town. If English zoologists are to keep up the high standard of previous Congresses, from the point of view of hospitality, it will be necessary for them to contribute handsomely to the funds of the Congress. It may be mentioned that Mr. P. L. Sclater, F.R.S., and Prof. Hickson, F.R.S, are the Treasurers for this meeting.

The Zoological Society has placed its house at the disposal of the Executive Committee, and all letters to the Treasurers or the Secretaries should be addressed to them at No. 3 Hanover Square.

We are requested by the Secretaries to say that they have taken every means in their power to send invitations and notices to all zoologists whom they have been able to reach ; but Secretaries are not infallible, and the Post Office itself has been known to fail in its duties before now. Any zoologist therefore, whether foreign or English, who has not yet received notices with regard to the Congress, should put himself into communication with the Secretaries at the above address.

\section{MODERN VIEWS OF THE RAINBOW.1}

ESCARTES'S theory of the rainbow, which is still found in all optical text-books, is hardly even a rough approximation to the true theory. It does not fully explain the ordinary bows, and fails entirely as regards the "spurious bows," improperly so called. Any close observer will, under favourable conditions, notice certain colours on the inside edge of the primary bow which are not consistent with the simple series of spectrum colours demanded by the venerable theory which may be said to mark the birth of modern science. These additional colours, chiefly red and green, recall the colours seen in Newton's rings at some distance from the centre, and at once suggest a similar origin. In a paper on "the intensity of light in the neighbourhood of a caustic" (Trans. Camb. Phil. Soc., 6, 1838, and 8, 1848), Airy has laid the foundation of an adequate theory of the rainbow which is gradually being worked out. With

I See a paper by J. M. Pernter, Wien. Ber., ro6, Part 2, a, 1897, and Abstracts of the Physical Society, No. 86 . 
a considerable amount of patience, Mr. J. M. Pernter has calculated the tints and the angular deviations of the rainbow colours for various sizes of rain-drops, and has devised experiments in support of his deductions. A parallel beam of sunlight after reflection and refraction in a spherical rain-drop does not emerge as a parallel beam, or as a bunch of parallel beams of various colours, but as a series of caustics of a somewhat complicated nature, in which the divergence of the colours, and hence their distinctness, separation, or coincidence depend upon the ratio of the radius of the drop to the wave-length of the light. The influence of size is very formidable in the smaller drops, say of $0^{\circ} \mathrm{O} \mathrm{mm}$. radius. This would be a very fine spray. The actual size of rain-drops is supposed to vary between $0^{\circ} \mathrm{I} \mathrm{mm}$. and 2.6 $\mathrm{mm}$., but the heavy drops of tropical rains are said to attain diameters of $3.4 \mathrm{~mm}$. Their size may be estimated by catching up and weighing a definite number, or by the more difficult method of diffraction. The tables drawn up by Pernter consider drops of twelve different sizes between $0^{\circ} 005$ and $\mathrm{I} \mathrm{mm}$. radius. In order to determine the resulting colours, Pernter selects eight of Maxwell's twenty-two colour equations, which number he finds sufficiently accurate. The first set of his tables state, for a point source of light, the sequence of colours, their composition in terms of red, green, and violet, the relative intensity (admixture of white, after Abney) and position on the colour triangle of each shade for various deviations between $42^{\circ} 20^{\prime}$ and $36^{\circ}$. These tables are then verified by experiments with cylindrical streams of drops, according to Babinet's method. With I mm. drops, Pernter observed red, orange-yellow, green, violet, blue' second violet, and then twenty-four secondaries or spurious colours, chiefly pinkish-violet and green or blue; after the twelfth violet came a whitish band, and then a reversal in the sequence of the colours. The $0.5 \mathrm{~mm}$. drops gave I I bows with 40 shades. The outer bow and its secondaries were also observed. Verifications in nature are hardly possible, as we cannot measure simultaneously the angles and the size of the drops producing the bow ; it is striking, however, that so very few angular measures are extant.

The white or pale rainbows (fog or mist bows) around moon and sun may appear paie owing to (I) the feeble intensity of the light, (2) the uneven size of the drops, and (3) the mixture of colours. The first cause is probably a real one; the second Pernter is inclined to reject, since the accompanying, often well-defined features such as "glories," Brocken spectra, \&c., and also his own tests require homogeneous conditions. As regards the third, Abney has proved that all colours of any shade disappear on being diluted with 75 parts of white, and Pernter's tables show that such cases may well occur. Further, Airy's theory renders white bands possible for all sizes of drops, and necessary for radii below $25 \mu$. As a stream of water of such fineness cannot be maintained, Pernter produced a mist spray by fixing a $0.5 \mathrm{~mm}$. glass tube in a lead pipe connected with the Innsbruck water mains (pressure 5 atmospheres), and directing the jet against a metallic plate; the size of drops was derived from measurements of diffraction rings. Drops of radius $5 \mu$ gave a yellow margin at $4 \mathbf{I}^{\circ} 59^{\prime}$, white between $4 \mathrm{I}^{\circ} 8^{\prime}$ and $38^{\circ} 27^{\prime}$, and then blue to $37^{\circ} 4 \mathrm{I}^{\prime}$; larger drops were more difficult to manage. From measurements of fog-bows on Ben Nevis, J. McConnell had in 1890 already calculated the sizes of the respective drops. But some of these observations speak of a red outer margin, for which Pernter looked in vain, and which his calculations do not indicate ; CrailheimGyllenskiöld (Swedish North Pole expedition, 1882) also describes the margin as of ochre colour. The classical white bows of Bouguer (I744) and of Scoresby (I 82I), however, do not fit into the theory at all, and were probably due, as the observers remarked, to ice-needles.
The general conclusions are interesting to meteorologists. The greater the drops, the more secondaries (spurious bows). A chief bow of intense pink and green (hardly any blue) indicates drops of diameters ranging from I to $2 \mathrm{~mm}$.; intense red always speaks for big drops. Secondaries of green and violet (the blue is masked by contrast) without yellow, immediately joining the chief bow, correspond to drops of $0.5 \mathrm{~mm}$., while five and more secondaries without white and without breaks mark drops of $0^{\circ} \mathrm{I} \mathrm{mm}$. A partly white bow is produced by drops of $0.06 \mathrm{~mm}$., and when the drops are still smaller, a real whire bow with orange-yellow and blue margins is the result. The net result of these elaborate investigations will be to add a new interest to a natural phenomenon already endowed with many associations of magic and beauty.

\section{EDUARD LINDEMANN AND OSCAR STUMPE.}

THE last days of the old year witnessed the removal by death of two astronomers who have rendered valuable services in the respective positions in which they were situated, though not occupying prominent places in the history of the science. Both are mentioned by the authorities under whom they served with the utmost respect, and their loss is acknowledged with profound regret.

Dr. Eduard Lindemann, who died suddenly on December $2 \mathrm{I}$, was born in Nishni-Novgorod in 1842 , and pursued his scientific studies in the Universities of Kasan and Dorpat The latter University he left in 1868 to enter the observatory of Pulkova, wherein he filled the office of scientific secretary. In this capacity he had the management of the library, and the preparation of the second part of the "Librorum in Bibliotheca Speculæe Pulkovensis contentorum Catalogus systematicus" was entrusted to him, and very admirably did he fulfil the trust. The duties of his office did not permit him to take a great part in the astronomical observations there carried on; but his tastes led him to take great interest in the Zollner photometer, and the series of careful measures which he made with that instrument have led to his being regarded as an authority in its use. His paper on the "Brilliancy of Bessel's Stars in the Pleiades," published in tome xxxii. of the Mem. de l'Acad. Imp. des Sci. de S. Petersbourg, is well known, and he has further used his measures to determine the scale of magnitude employed in the Bonn Durchmusterung.

The second astronomer whose death (at the early age of thirty-five) we have regretfully to mention is Dr. Oscar Stumpe, well known for his contribution on the motion of the solar system. Dr. Stumpe's early life appears to have been one of great hardship and a severe struggie against adverse circumstances. When ten years old he lost his father, but, in face of all difficulties, he determined to win his way to the Berlin University as a student of science. This he accomplished in 1883 , though he had had occasionally in previous years to interchange the parts of student and teacher in order to obtain a livelihood and be enabled to continue his career. Even at Berlin, his studies of mathematics and astronomy were interrupted by his duties as a shorthand writer in the Government and Law Courts. From Berlin he went to Bonn, and became a teacher in a private institution. Here he appears to have prepared the heavy calculations which he afterwards incorporated in his inaugural dissertation on the Solar Motion. In this work, Dr. Stumpe based his computations on I054 stars, whose annual proper motion exceeded $0^{\prime \prime} \cdot 16$ in the arc of a great circle. The peculiar feature in the treatment was the introduction of a term

$$
\text { NO. I 474, VOL. 57] }
$$

